\title{
The efficacy of employing full-time midwives in community maternal and child health services
}

\author{
Fujiko OMINE ${ }^{1}$, Yoko TAMASHIRO ${ }^{1}$, Mitsue NAKAMURA ${ }^{1}$, \\ Tugiko GIMA ${ }^{1}$, Miyoko UZA ${ }^{1}$ and Kiyoko KAMIBEPPU ${ }^{2}$
}

Communities were divided into three categories, those employing full-time midwives ( $\mathrm{M}-\mathrm{com}-$ munities), and those employing public health nurses (PHNs) either with midwife license (PM-communities) or without ( $\mathrm{P}-$ communities $)$. Maternal and child health $(\mathrm{MCH})$ services rendered and their intent to employ more midwives were investigated. A questionnaire concerning these achievements and the reasons for considering employing more midwives was sent to 579 communities with a population greater than 50,000 in 2002, and 285 valid responses were obtained. These consisted of 32, 121 and 132 responses from $\mathrm{M}^{-}, \mathrm{PM}^{-}$and $\mathrm{P}^{-}$communities, respectively. A statistical analysis was made of the variables by chi-square test.

$75.2 \%$ of these PM-communities responded for various reasons that they had no greater need for midwives, indicating that the midwife license is not highly valued. $\mathrm{M}$-communities had the highest intention of employing more midwives at $53.1 \%$, and also attained higher fulfillments in $\mathrm{MCH}$ services than the others, which provided sub-optimal service in many areas of care. Although some PHNs had midwife licenses, their midwifery expertise was not fully provided for. Considering the often low general level of $\mathrm{MCH}$ services and the relatively higher achievements of the $\mathrm{M}$-communities, increased employment of full-time midwives should be considered by the administrators concerned.

Key words : maternal and child health service, public health nurse, midwife license, full-time midwife, midwifery education

\section{Introduction}

More than 20 years have passed since nursing students were first eligible for the three nursing licenses of public health nurse (PHN), midwife and nurse in 4-year university courses, and such professionals now fulfill valuable roles in their communities. In particular are the considerable number of professionals engaging in regional maternal and child health $(\mathrm{MCH})$ services as PHNs with midwife license in the 20 s to 50 s age range. Even though they have midwife licenses, it is commonly perceived that very few use it in their jobs. The present study was performed against this background to research the activities of these PHNs.

Though this study was based on our paper published in 2002, which dealt with the necessity of midwives as full-time workers and their total numbers, here we discuss the specific roles of mid-

\footnotetext{
${ }^{1}$ School of Health Sciences, Faculty of Medicine, University of the Ryukyus

${ }^{2}$ School of Health Sciences \& Nursing, Faculty of Medicine, the University of Tokyo
} 
wives and PHNs with midwife license, focusing on their activities in $\mathrm{MCH}$ services in the community.

There were about 77,000 midwives in Japan at the peak in the late 1940s. That number dropped to 55,000 in the mid-1950s and has steadily declined to around 24,340 in 2002. This drastic reduction is likely due to changes in midwifery training schools driven by changes in the law governing midwives, nurses and PHNs. These changes converted nursing schools into universities and allowed the students to take the midwife course as an option in the unified curricula, causing a significant extra burden to them in a 4-year nursing education. Additionally, transferring the birth-place to hospitals deprived midwives of their work source ; further the steady decrease in the birth rate in Japan since the late 1940s also accounts for some of the decline.

Of the 24,340 midwives working in Japan in 2002 , only $1,706(7.0 \%)$ were employed as community-based practitioners and $702(2.9 \%)$ worked in public health centers. Why the dramatic reduction in the numbers of midwives? And how do communities decide on the employment of midwives? This study aims to answer these questions by identifying the forces and barriers that dictate employment of midwives.

\section{Methods}

The subjects in this study were the staff working for $\mathrm{MCH}$ services in communities with populations greater than 50,000 in 2002 that employed two or more midwives (Japan Nursing Society, 2002). We mailed a questionnaire to these communities and requested prompt responses. The questionnaire contained the following requests : (1) the name of the questionnaire respondent and his/her official position, (2) the population, number of births and birth rate in the community, (3) the activities of midwives in the community and whether or not an increase in midwife staff was being considered, including reasons, and (4) details concerning the professionals or practitioners offering $\mathrm{MCH}$ services, and the perceived need for midwives in each $\mathrm{MCH}$ service.

The relevant $\mathrm{MCH}$ services provided were as follows : (1) pregnancy notification and issuance of MCH handbook, (2) class activity in the form of lectures on puberty, the premarital or honeymoon stage, the maternal or parental stage, and homenursing for child care, (3) health instruction on pubertal experiences, postnatal care, prenatal visits, and temporary nurseries for infants, (4) health consultation concerning pregnancy and postpartum, infants, family planning and menopause, (5) regular health checks for young infants, $18^{-}$monthold infants, and 3-year-old children, (6) visiting service for the pregnant and the neonate, (7) educating midwife and nursing students, and (8) telephone consultation on infant care, puberty hotlines, and domestic violence (DV) hotlines. The communities were divided into three categories, those employing full-time midwives ( $\mathrm{M}$-communities), and PHNs either with midwife license (PM-communities) or without ( $\mathrm{P}-$ communities $)$. Statistical analysis of the variables was carried out using the chi-square test.

\section{Results}

\section{On the response}

The questionnaire was sent to the 579 relevant communities, of which 285 communities responded. Of the respondents, 251 (88.1\%) were from PHNs and 34 (11.9\%) from all others. Regarding the community size, $253(88.8 \%)$ respondents were from cities, 31 (10.9\%) from the 23 suburbs of Tokyo and other cities and one from a village. Overall, this represents a $49.2 \%$ response rate. The population of communities that responded ranged from a low of 50,100 to a high of 3,404,077. 
Table 1 Data for communities categorized by the qualifications of their full-time nursing staff. (Numbers and sizes of communities, and the proportion considering further employment of midwives)

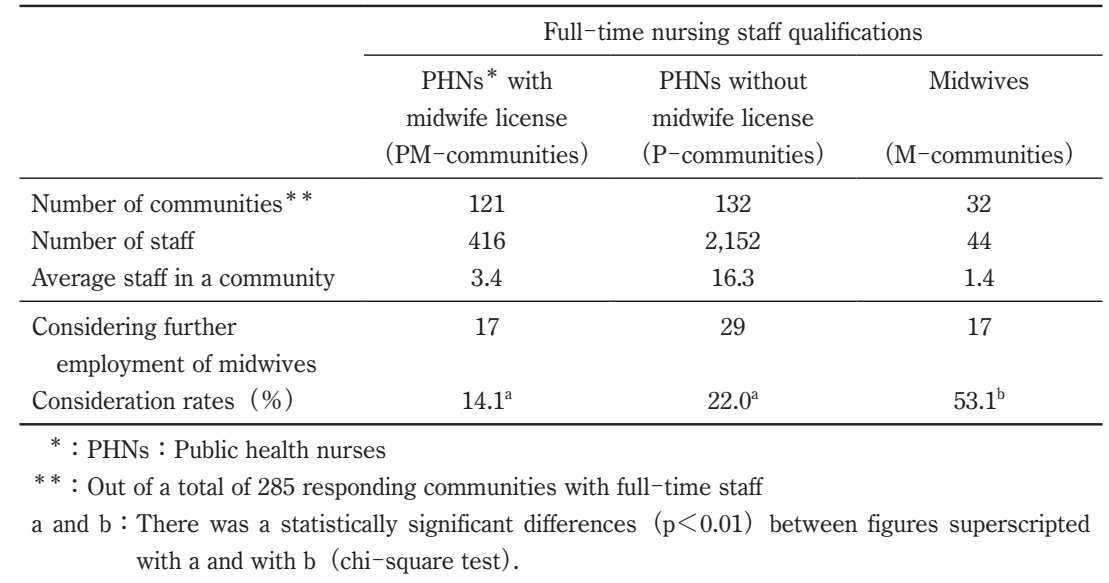

Most responders were located in communities with populations between 50,100 and 100,000 people. The number of births in the responding communities ranged from 298 to 33,123 , and birth rates from $5.5 \%$ oto $18.8 \%$ with an average of $9.5 \%$.

\section{The types of full-time nursing staff}

Table 1 shows the different types of full-time nursing staff in all the responding communities. There were 44 midwives working in 32 communities ( $11.2 \%$ of the 285 responding communities), mostly allocated to communities of 1 to 5 regular nursing staff.

On the other hand, according to the data (Japan Nursing Society. 2002) $40 \%$ to $60 \%$ of midwives were working as part-time workers or consignees in communities served by 1 to 10 regular nursing staff. Of the 24,340 midwives in 2002, only 702 $(2.9 \%)$ worked in official communities or public health centers.

Among the 285 responding communities, there were $121(42.5 \%)$ that allocated 416 PHNs with midwife license, or 3.4 staff per community on average (Table 1).

\section{Consideration of increased employment of midwives as full-time workers}

Table 1 shows the consideration of further employment of midwives in the different types of communities. As indicated, 53.1\% of communities currently employing midwives were considering employing more, whereas of the communities employing PHNs with or without midwife license (PM-and $\mathrm{P}$-communities, respectively) only $14.1 \%$ and $22.0 \%$ respectively were considering their additional employment. These values represent a significantly different intent $(\mathrm{p}<0.01)$. As a whole, $\mathrm{M}$-communities were thus more likely to consider employing additional midwives.

\section{The necessity for employing midwives} and the reasons given

When asked why they needed full-time midwives, 92 communities responded with a variety of reasons, which are categorized into 7 groups in Table 2-a. The most common reasons were as follows : 1) to provide $\mathrm{MCH}$ services, 2) to enhance $\mathrm{MCH}$ services, and 3) difficulty for the staff to work effectively with part-time workers or con- 
Table 2-a The reasons given for the communities to need midwives as full-time workers N (\%)

\begin{tabular}{|c|c|c|c|c|}
\hline \multirow{2}{*}{$\begin{array}{l}\text { The reasons given for the communities to } \\
\text { need midwives as full-time workers }\end{array}$} & \multirow{2}{*}{$\begin{array}{l}\text { Total } \\
\text { responses }\end{array}$} & \multicolumn{2}{|c|}{$\begin{array}{c}\text { Communities employing PHNs } \\
\text { with or without midwife license } \\
\text { (employing no midwives as full-time } \\
\text { workers) }\end{array}$} & $\begin{array}{l}\text { Communities } \\
\text { employing at least } \\
\text { one full-time } \\
\text { midwife }\end{array}$ \\
\hline & & $\begin{array}{c}\text { Licensed } \\
\text { (PM-communities) } \\
\mathrm{N}=121^{*}\end{array}$ & $\begin{array}{c}\text { Unlicensed } \\
\text { (P-communities) } \\
\mathrm{N}=132^{*}\end{array}$ & $\begin{array}{l}\text { (M-communities) } \\
\quad \mathrm{N}=32^{*}\end{array}$ \\
\hline 1. To provide $\mathrm{MCH}^{* *}$ services & $42(14.7)$ & $16(13.2)$ & $21(15.9)$ & $5(15.6)$ \\
\hline 2. To enhance MCH services & $32(11.2)$ & $11(9.1)$ & $14(10.6)$ & $7(21.9)$ \\
\hline $\begin{array}{l}\text { 3. Difficulty for the staff to work effectively } \\
\text { with part-time workers or consignees }\end{array}$ & $7(2.5)$ & 0 & $5(3.8)$ & $2(5.7)$ \\
\hline $\begin{array}{l}\text { 4. Midwifery specialists are requested from } \\
\text { the communities }\end{array}$ & $6(2.1)$ & 0 & $5(3.8)$ & $1(3.1)$ \\
\hline $\begin{array}{l}\text { 5. Full-time Midwife workers are more } \\
\text { helpful than those of part-time workers }\end{array}$ & $3(1.1)$ & $1(0.8)$ & $1(0.8)$ & $1(3.1)$ \\
\hline $\begin{array}{l}\text { 6. PHNs }{ }^{* * *} \text { and midwives should cooperate } \\
\text { and communicate as } \mathrm{MCH} \text { supporters }\end{array}$ & $1(0.4)$ & 0 & $1(0.8)$ & 0 \\
\hline $\begin{array}{l}\text { 7. Midwives are preferable in each } \mathrm{MCH} \\
\text { consultation }\end{array}$ & $1(0.4)$ & 0 & $1(0.8)$ & 0 \\
\hline Total communities responding & $92(32.3)$ & $28(23.1)$ & $48(36.4)$ & $16(50.0)$ \\
\hline
\end{tabular}

Table 2-b The reasons given for the communities not to need midwives as full-time workers $\mathrm{N}$ (\%)

\begin{tabular}{|c|c|c|c|c|}
\hline \multirow{2}{*}{$\begin{array}{l}\text { The reasons given for the communities not to } \\
\text { need midwives as full-time workers }\end{array}$} & \multirow{2}{*}{$\begin{array}{l}\text { Total } \\
\text { responses }\end{array}$} & \multicolumn{2}{|c|}{$\begin{array}{c}\text { Communities employing PHNs } \\
\text { with or without midwife license } \\
\text { (employing no midwives as full-time } \\
\text { workers) }\end{array}$} & \multirow{2}{*}{$\begin{array}{c}\text { Communities } \\
\text { employing at least } \\
\begin{array}{c}\text { one full-time } \\
\text { midwife }\end{array} \\
\text { (M-communities) } \\
\mathrm{N}=32^{*}\end{array}$} \\
\hline & & $\begin{array}{c}\text { Licensed } \\
(\mathrm{PM}-\text { communities }) \\
\mathrm{N}=121^{*}\end{array}$ & $\begin{array}{c}\text { Unlicensed } \\
\text { (P-communities) } \\
\mathrm{N}=132^{*}\end{array}$ & \\
\hline $\begin{array}{l}\text { 1. Midwives were only needed for part-time or } \\
\text { consigned jobs }\end{array}$ & $75(26.3)$ & $39(32.2)$ & $34(25.8)$ & $2(5.7)$ \\
\hline $\begin{array}{l}\text { 2. Assigning higher priority to hiring PHNs } \\
\text { and dietitians }\end{array}$ & $28(9.8)$ & $19(15.7)$ & $5(3.8)$ & $4(11.4)$ \\
\hline $\begin{array}{l}\text { 3. The level of } \mathrm{MCH} \text { services did not warrant } \\
\text { full-time workers }\end{array}$ & $23(8.1)$ & $7(5.8)$ & $16(0.8)$ & 0 \\
\hline $\begin{array}{l}\text { 4. } \mathrm{MCH} \text { services were being achieved by } \\
\text { adequate numbers of PHNs }\end{array}$ & $15(5.3)$ & $5(4.1)$ & $9(6.8)$ & $1(2.9)$ \\
\hline $\begin{array}{l}\text { 5. Financial shortfall precluded further } \\
\text { employment of full-time workers }\end{array}$ & $15(5.3)$ & $6(5.0)$ & $9(6.8)$ & 0 \\
\hline $\begin{array}{l}\text { 6. MCH services were adequately provided by } \\
\text { PHNs with midwife license }\end{array}$ & $13(4.6)$ & $13(10.7)$ & 0 & 0 \\
\hline 7. Midwives are not needed & $7(2.5)$ & $1(0.8)$ & $5(3.8)$ & $1(3.1)$ \\
\hline $\begin{array}{l}\text { 8. Possible to cooperate with the midwives in } \\
\text { hospitals or the public health center }\end{array}$ & $2(0.7)$ & $1(0.8)$ & 0 & $1(3.1)$ \\
\hline Total communities responding & $178(62.5)$ & $91 \quad(75.2)$ & $78(59.1)$ & $9(28.1)$ \\
\hline
\end{tabular}

\footnotetext{
$*:$ The number of communities responding

$* *: \mathrm{MCH}:$ Maternal and child health

$* * *$ : PHNs : Public health nurses
} 
signees, of which the first two accounted for 74 out of 92 respondees $(80.4 \%)$.

Regarding the number of reasons raised for needing midwives as full-time workers, there was no statistical difference between the distributions in $\mathrm{M}^{-}$and PM-communities. Out of a total of 92 reasons raised, 16 were from $\mathrm{M}$-communities, and 28 from $\mathrm{PM}-$ communities. These were $17.4 \%$ and $30.4 \%$ of the total responses respectively. The rest were from $\mathrm{P}$-communities. However, a much higher proportion of $\mathrm{M}-$ communities $(50 \%)$, gave reasons for their requirement.

Conversely, when asked why they do not need full-time midwives, there were 178 responses to this question (Table $2-b)$. The reasons were as follows : 1) midwives were only needed for parttime or consigned jobs, 2) assigning higher priority to hiring PHNs and dietitians, 3) the level of $\mathrm{MCH}$ services did not warrant full-time workers. The next reasons in order were that 4) $\mathrm{MCH}$ services were being achieved by adequate numbers of PHNs, 5) financial shortfall precluded further employment of full-time workers, and 6) $\mathrm{MCH}$ services were adequately provided by PHNs with midwife license. This last reason was raised by only $13 \mathrm{PM}$-communities. Overall, a higher proportion of $\mathrm{PM}^{-}$and $\mathrm{P}$-communities raised reasons than did $\mathrm{M}-$ communities.

\section{Necessity for midwives in each $\mathrm{MCH}$ service}

Communities provided the $\mathrm{MCH}$ services shown in Table 3 in different ways. Accordingly, the necessity for midwives in each $\mathrm{MCH}$ service differed between the communities. When we asked communities whether they needed midwives in each $\mathrm{MCH}$ service or not, regardless of current employment of full-time midwives, the affirmative response rates by service and community type were shown in Table 3. As this Table shows, more than $80 \%$ of all three types of community felt the need for midwives in four $\mathrm{MCH}$ service areas, namely, 1) class activities on the maternal or parental stage, 2) health instruction on postnatal care, 3) visiting services for the pregnant, and 4) visiting services for the neonate. There were no statistically significant differences among the three communities in these 4 services.

However, this same high proportion of $\mathrm{M}-\mathrm{com}$ munities $(>80 \%)$ felt this need in a further 11 MCH services. This need for midwives was also significantly greater than in the other two communities in 11 services.

\section{The scope of $\mathrm{MCH}$ services provided}

The scope of MCH services provided was different from community to community. We asked communities to indicate which services they provided, and the responses are shown in Table 4 as percentages. As this Table shows, there were seven services that all three communities provided at a level higher than $90 \%$, namely 1) pregnancy notification and issuance of $\mathrm{MCH}$ handbook, 2) class activity in the maternal or parental stage, 3) health consultation on infants, 4, 5) health checks for 18 month-old infants and 3 year-old children and 6,7$)$ visiting services for the pregnant and the neonate. For these seven highest-offered services, there were no statistically significant differences among the communities with regard to employment of midwives or PHNs with or without midwife license.

There were a further five services offered at relatively high rates (60\% to $90 \%)$, which were 1) class activity of home-nursing for child care, 2) health consultation for the pregnancy and postpartum care, 3) health checks for young infants, 4) education midwife and nursing students, and 5) telephone consultation on baby care. For these five services, there were no statistically significant dif- 
Table 3 Affirmative response rates regarding the necessity for midwives in each $\mathrm{MCH}$ service, arranged by type of community

\begin{tabular}{|c|c|c|c|}
\hline \multirow{2}{*}{ MCH services } & \multicolumn{2}{|c|}{$\begin{array}{c}\text { Communities employing PHNs } \\
\text { with or without midwife license } \\
\text { (employing no midwives as full-time workers) }\end{array}$} & \multirow{2}{*}{$\begin{array}{c}\text { Communities } \\
\text { employing at least } \\
\text { one full-time midwife } \\
\begin{array}{c}\text { (M-communities) } \\
\mathrm{N}=32^{*}\end{array}\end{array}$} \\
\hline & $\begin{array}{c}\text { Licensed } \\
\text { (PM-communities) } \\
\mathrm{N}=121^{*}\end{array}$ & $\begin{array}{c}\text { Unlicensed } \\
\text { (P-communities) } \\
\mathrm{N}=132^{*}\end{array}$ & \\
\hline $\begin{array}{l}\text { 1. Pregnancy notification and issuance of } \mathrm{MCH} \\
\text { handbook }\end{array}$ & $29.3\left(34^{\mathrm{a}}, 116\right)^{* *}$ & $25.4\left(30^{\mathrm{a}}, 118\right)^{* *}$ & $93.5\left(29^{b}, 31\right)^{* *}$ \\
\hline \multicolumn{4}{|l|}{ 2. Class activity } \\
\hline lectures on puberty & $66.7(34,51)$ & $70.7(29,41)$ & $85.0(17,20)$ \\
\hline premarital or honeymoon stage & $69.0(20,29)$ & $74.1(20,27)$ & $90.0(9,10)$ \\
\hline maternal or parental stage & $88.8(103,116)$ & $91.1(113,124)$ & $93.8(30,32)$ \\
\hline home-nursing for child care & $20.8\left(16^{\mathrm{a}}, 77\right)$ & $24.3\left(18^{\mathrm{a}}, 74\right)$ & $64.0\left(16^{\mathrm{b}}, 25\right)$ \\
\hline \multicolumn{4}{|l|}{ 3. Health instruction } \\
\hline pubertal experiences & $68.2(30,44)$ & $77.5(31,40)$ & $80.0(16,20)$ \\
\hline postnatal care & $85.2(23,27)$ & $97.0(32,33)$ & $92.9(13,14)$ \\
\hline prenatal visits & $28.6\left(6^{\mathrm{a}}, 21\right)$ & $66.7\left(20^{\mathrm{b}}, 30\right)$ & $75.0\left(9^{\mathrm{b}}, 12\right)$ \\
\hline temporary nurseries for infants & $13.0(3,23)$ & $24.0(6,25)$ & $36.4(4,11) * * *$ \\
\hline \multicolumn{4}{|l|}{ 4. Health consultation } \\
\hline the pregnancy and postpartum & $67.0\left(67^{\mathrm{a}}, 100\right)$ & $79.6\left(74^{\mathrm{b}}, 93\right)$ & $86.7\left(26^{\mathrm{b}}, 30\right)$ \\
\hline infants & $32.5\left(37^{\mathrm{a}}, 114\right)$ & $42.3\left(47^{\mathrm{a}}, 111\right)$ & $74.2\left(23^{\mathrm{b}}, 31\right)$ \\
\hline family planning & $79.6(43,54)$ & $80.4(45,56)$ & $95.8(23,24)$ \\
\hline menopause & $45.0\left(18^{\mathrm{a}}, 40\right)$ & $55.6\left(30^{\mathrm{a}}, 54\right)$ & $95.0\left(19^{b}, 20\right)$ \\
\hline \multicolumn{4}{|l|}{ 5. Health-check } \\
\hline young infants & $31.9\left(30^{\mathrm{a}}, 94\right)$ & $34.5\left(38^{\mathrm{a}}, 110\right)$ & $88.9\left(24^{\mathrm{b}}, 27\right)$ \\
\hline 18-month-old infants & $10.2\left(11^{\mathrm{a}}, 108\right)$ & $11.6\left(13^{\mathrm{a}}, 112\right)$ & $58.6\left(17^{\mathrm{b}}, 29\right)$ \\
\hline 3-year-old children & $8.3\left(9^{a}, 108\right)$ & $7.1\left(8^{\mathrm{a}}, 112\right)$ & $50.0\left(14^{\mathrm{b}}, 28\right)$ \\
\hline \multicolumn{4}{|l|}{ 6. Visiting service } \\
\hline the pregnant & $89.9(107,119)$ & $90.2(111,123)$ & $93.8(30,32)$ \\
\hline the neonate & $88.7(104,120)$ & $89.7(113,126)$ & $93.8(30,32)$ \\
\hline 7. Educating midwife and nursing students & $26.2\left(27^{\mathrm{a}}, 103\right)$ & $30.9\left(30^{\mathrm{a}}, 97\right)$ & $79.3\left(23^{\mathrm{b}}, 29\right)$ \\
\hline \multicolumn{4}{|l|}{ 8. Telephone consultation } \\
\hline baby care & $45.5\left(45^{\mathrm{a}}, 99\right)$ & $52.5\left(52^{\mathrm{a}}, 99\right)$ & $92.3\left(24^{\mathrm{b}}, 26\right)$ \\
\hline puberty hotlines & $58.6\left(17^{\mathrm{a}}, 29\right)$ & $66.7\left(18^{\mathrm{a}}, 27\right)$ & $100.0\left(11^{\mathrm{b}}, 11\right)$ \\
\hline DV hotlines & $25.0\left(6^{\mathrm{a}}, 24\right)$ & $41.7\left(10^{\mathrm{a}}, 24\right)$ & $83.3\left(5^{b}, 6\right)$ \\
\hline
\end{tabular}

* : Responding communities.

** : The numerals are the percentage expressing the need for midwives in each MCH service, with number of communities in parenthesis

$\mathrm{a}$ and $\mathrm{b}$ : There was a statistically significant differences (at least more than $\mathrm{p}<0.05$ ) between figures superscripted with a and with b (chi-square test).

$* * *$ : When the number of communities responding was less than 5 , the analysis was done with Fisher's exact test.

ferences among the communities except for class activity in home nursing for childcare.

On the contrary, there were four services offered at relatively low rates $(20 \%$ to $70 \%): 1)$ class activity in lectures on puberty, 2) health instruction on pubertal experiences, 3, 4) health consultation on family planning and menopause. Provision of these four services was statistically higher in $\mathrm{M}$-communities than the others.

There were five services accomplished at the 
Table 4 The percentage of communities providing each service, arranged by type of community

\begin{tabular}{|c|c|c|c|}
\hline \multirow{2}{*}{$\mathrm{MCH}$ services } & \multicolumn{2}{|c|}{$\begin{array}{l}\text { Communities employing PHNs } \\
\text { with or without midwife license } \\
\text { (employing no midwives as full-time workers) }\end{array}$} & \multirow{2}{*}{$\begin{array}{c}\text { Communities } \\
\text { employing at least } \\
\text { one full-time midwife } \\
\begin{array}{c}\text { (M-communities) } \\
\mathrm{N}=32^{*}\end{array}\end{array}$} \\
\hline & $\begin{array}{c}\text { Licensed } \\
\text { (PM-communities) } \\
\mathrm{N}=121^{*}\end{array}$ & $\begin{array}{c}\text { Unlicensed } \\
(\mathrm{P}-\text { communities }) \\
\mathrm{N}=132^{*}\end{array}$ & \\
\hline $\begin{array}{l}\text { 1. Pregnancy notification and issuances of } \mathrm{MCH} \\
\text { handbook }\end{array}$ & $96.7(117,121)^{* *}$ & $96.2(126,131)^{* *}$ & $96.9(31,32)^{* *}$ \\
\hline \multicolumn{4}{|l|}{ 2. Class activity } \\
\hline lectures on puberty & $24.2\left(29^{\mathrm{a}}, 120\right)$ & $17.8\left(23^{\mathrm{a}}, 129\right)$ & $56.3\left(18^{\mathrm{b}}, 32\right)$ \\
\hline premarital or honeymoon stage & $5.0(6,119)$ & $4.0(5,126)$ & $10.0(3,30) * * *$ \\
\hline maternal or parental stage & $97.5(117,120)$ & $97.7(128,131)$ & $100.0(32,32)$ \\
\hline home-nursing for child care & $63.2\left(74^{\mathrm{a}}, 117\right)$ & $58.9\left(76^{\mathrm{a}}, 129\right)$ & $87.5\left(28^{\mathrm{b}}, 32\right)$ \\
\hline \multicolumn{4}{|l|}{ 3. Health instruction } \\
\hline pubertal experiences & $26.9\left(32^{\mathrm{a}}, 119\right)$ & $18.1\left(23^{\mathrm{a}}, 127\right)$ & $43.8\left(14^{\mathrm{b}}, 32\right)$ \\
\hline postnatal care & $14.7\left(17^{\mathrm{a}}, 116\right)$ & $6.3\left(8^{\mathrm{a}}, 127\right)$ & $35.5\left(11^{\mathrm{b}}, 31\right)$ \\
\hline prenatal visits & $5.3(6,114)$ & $7.1(9,126)$ & $12.9(4,31) * * *$ \\
\hline temporary nurseries for infants & $8.7(10,115)$ & $4.8(6,125)$ & $16.1(5,31)$ \\
\hline \multicolumn{4}{|l|}{ 4. Health consultation } \\
\hline the pregnancy and postpartum & $81.7(98,120)$ & $73.8(96,130)$ & $93.5(29,31)$ \\
\hline infants & $99.2(119,120)$ & $97.7(127,130)$ & $100.0(31,31)$ \\
\hline family planning & $40.2\left(47^{\mathrm{a}}, 117\right)$ & $37.8\left(48^{\mathrm{a}}, 127\right)$ & $74.2\left(23^{\mathrm{b}}, 31\right)$ \\
\hline menopause & $29.1\left(34^{\mathrm{a}}, 117\right)$ & $33.3\left(43^{\mathrm{a}}, 129\right)$ & $61.3\left(19^{\mathrm{b}}, 31\right)$ \\
\hline \multicolumn{4}{|l|}{ 5. Health-check } \\
\hline young infants & $81.7(98,120)$ & $91.5(118,129)$ & $87.5(28,32)$ \\
\hline 18-month-old infants & $95.9(116,121)$ & $100(130,130)$ & $96.9(31,32)$ \\
\hline 3-year-old children & $97.5(115,118)$ & $100(123,123)$ & $93.1(27,29)$ \\
\hline \multicolumn{4}{|l|}{ 6. Visiting service } \\
\hline the pregnant & $97.5(118,121)$ & $97.7(128,131)$ & $100.0(32,32)$ \\
\hline the neonate & $99.2(120,121)$ & $99.2(130,131)$ & $100.0(32,32)$ \\
\hline 7. Educating midwife and nursing students & $90.0(108,120)$ & $89.8(115,128)$ & $93.8(30,32)$ \\
\hline \multicolumn{4}{|l|}{ 8. Telephone consultation } \\
\hline baby care & $85.7(102,119)$ & $86.8(112,129)$ & $83.9(26,31)$ \\
\hline puberty hotlines & $12.2(14,115)$ & $11.0(13,118)$ & $27.3(6,22)$ \\
\hline DV hotlines & $8.2\left(9^{\mathrm{a}}, 110\right)$ & $9.6\left(11^{\mathrm{a}}, 115\right)$ & $24.1\left(7^{\mathrm{b}}, 29\right)$ \\
\hline
\end{tabular}

$*$ : Responding communities.

** : The numerals are the percentage of communities providing each $\mathrm{MCH}$ service, with number of communities in parenthesis

$\mathrm{a}$ and $\mathrm{b}$ : There was a statistically significant differences (at least more than $\mathrm{p}<0.05$ ) between figures superscripted with a and with b (chi-square test).

$* * *$ : When the number of communities responding was less than 5 , the analysis was done with Fisher's exact test.

lowest rates $(<20 \%): 1)$ class activity in the premarital or honeymoon stage, 2, 3) health instruction on prenatal visits and temporary nurseries for infants, 4, 5) telephone consultation on puberty hotlines, and DV hotlines. For these five services, there were no statistically significant differences except for telephone consulting on DV hotlines, where $\mathrm{M}$-communities had higher provision rates than the others.

There were statistical differences in seven services out of 22 (by at least $\mathrm{p}<0.05$ ) as delineated by superscripts a and b (Table 4). For MCH services 
as a whole, the statistically significant differences were observed predominantly in those services with relatively lower provision rates.

\section{Discussion}

\section{The perceived need for the employment} of midwives as full-time workers

As Table 1 shows, there were 44 full-time midwives working in 32 communities with populations of 50,000 or more, which was $11.2 \%$ of the 285 communities that responded to the questionnaire. This number of responding communities employing only midwives, or $\mathrm{M}$-communities, might be too small, considering that there were 702 midwives working in the communities.

\section{Implications of comparative numbers of PHN and midwife staff}

As Table 1 shows, most communities employed PHNs as the full-time MCH workers. Of the 285 communities that responded, 121 employed PHNs with midwife licenses. In these communities, there were 416 working staff, with an average of 3.4 staff per community. In contrast, there were only $32 \mathrm{M}-$ communities with an average work force of only1.4 staff per community. This may suggest that the health services in the communities employing PHNs are adequately provided by the PHNs themselves, and that professional midwives in those communities would be deprived of the opportunity to perform their professional services.

\section{Midwife staff have the highest require- ment for more midwives}

Table 1 shows the responses of the three communities when asked if they would consider employing more full-time midwives. $53.1 \%$ of $\mathrm{M}^{-}$ communities considered employing more midwives, but only $14.1 \%$ and $22.0 \%$ of $\mathrm{PM}-$ and $\mathrm{P}-$ communities did, respectively, representing a sta- tistically significant difference $(\mathrm{p}<0.01)$.

\section{The reasons to need full-time midwives}

There were many different reasons given, when the respondents were asked why they needed fulltime midwives (Table $2-\mathrm{a}$ ). The most common reasons, given by about $80 \%$ of respondents, were to provide $\mathrm{MCH}$ services and to enhance $\mathrm{MCH}$ services. This may well indicate that the communities sought out midwives as specialists for their highly professional skills in the health services.

On the other hand, more reasons were given for not needing midwives in $\mathrm{MCH}$ services than for needing them. Out of $32 \mathrm{M}$-communities, $16 \mathrm{com}$ munities raised reasons to need midwives, suggesting that they might appreciate the work of midwives more, and admit their need of them more easily. Out of 178 responses for reasons not to need midwives in $\mathrm{MCH}$ services, 91 (or 51.1\%) were from PM-communities. Thus $75.2 \%$ of the $121 \mathrm{PM}$-communities that responded to the questionnaire had expressed that they did not require midwives, but only $10.7 \%$ replied that PHNs with midwife license were adequately providing the services. This may suggest that such responses are reflexes denying the need of midwives in the communities, for $\mathrm{PHNs}$ were likely undertaking the jobs of midwives, whether they had the midwife license or not.

Kano and Komatsu (2001) described that as higher professional skills were increasingly required, more training and further education were needed to meet these demands. It therefore seems an appropriate time to discuss how to improve the initial education of midwives, and also how to enhance their postgraduate education.

On the other hand, $70 \%(126 / 178)$ of the reasons not to need midwives were either 1) midwives were only needed for part-time or consigned jobs, 2) assigning higher priority to employ- 
ing other staff such as PHNs or dietitians, or 3) the level of $\mathrm{MCH}$ services did not warrant full-time workers (Table 2-b). These responses may suggest that these communities were committed to employing $\mathrm{MCH}$ generalists rather than specialists. However, the communities should employ midwives, as they can function as both generalists and specialists in $\mathrm{MCH}$ services.

\section{Necessity of midwives in each service}

The biggest difference in the perceived need for midwives in the communities employing these workers was for pregnancy notification and issuance of $\mathrm{MCH}$ handbooks, there being a high need in $\mathrm{M}$-communities.

Indeed, as Table 3 shows, the need for midwives in $\mathrm{M}$-communities was in a higher range of values in all $\mathrm{MCH}$ services except four, for which all 3 communities rated the need higher than $80 \%$.

There was a statistically significant high proportion of $\mathrm{M}$-communities providing 7 of the $22 \mathrm{MCH}$ services, or more than $30 \%$ of the total. It showed that as a whole, $\mathrm{M}$-communities had a high need for midwives in these areas.

In other words, it might be said that the other communities had a low perceived need for midwives, as there were no significant differences in the rates between $\mathrm{PM}-$ and $\mathrm{P}$-communities. It might also suggest that licensed PHNs did not contribute to increasing the necessity of midwives.

As a whole in the $\mathrm{MCH}$ services, the statistically significant differences were observed collectively in the services with relatively lower fulfillment rates.

\section{General discussion}

Looking at the total number of responses irrespective of community type, there were almost twice as many reasons given not to need midwives as there were reasons to need them. It could be concluded that most communities regard $\mathrm{PHNs}$ as more desirable for providing $\mathrm{MCH}$ services than the highly specialized midwives because of the convenience, especially in $\mathrm{PM}-$ communities. Given this to be the case, it may well be that even midwives with their more professional skills would be no different to PHNs in their job performance. However, the current trend in midwife education in our country is to incorporate midwife training into the training programs of other nursing professionals (Kato, 2000). Midwife educators should be warned that it may not be adequate to train midwives via a 4-year university curriculum, as this will produce less practicing midwives. Specialized midwives should be employed instead of PHNs with midwife license. Based on the current situation, we need to consider the relevance of present midwifery training curricula that are making students collectors of licenses but not real midwifery practitioners.

Considering the role of nursing professionals in the communities, Kondo (1999) stated that it should be divided into two: one for specialists to meet the need for specialized care and the other for generalists to meet the general health care needs. The generalists should be trained first in fundamental nursing education, and the specialists in midwifery education.

The curricula in specialist midwifery education were focused on pregnancy, childbirth, and confinement. But now it is unified into a 4-year course in university for nurses and PHNs. In this situation, even midwifery students who passed the examination to become midwives are still neither specialists nor generalists, but are considered as nonaffiliated nursing staff. Right after graduation, the midwives are sent into the communities without further training or direction concerning the advancement of their profession.

In general, M-communities had higher fulfill- 
ment rates in almost all $\mathrm{MCH}$ services than those with no full-time workers. According to the report of the Japanese Midwives' Association (Kato, 2001), very few midwives were participating in the planning or management of $\mathrm{MCH}$ services in the communities, but rather most were engaged in technical jobs representing a small number of midwives in the field, and the PHNs occupied most of the $\mathrm{MCH}$ leadership positions. The midwives were instead engaged in restricted activities such as care for newborn babies. This situation suggests that there is a lack of cooperation between midwives and PHNs in terms of equal job opportunities as well as the lack of a well defined role for the former as health care workers.

This trend was confirmed by Noguchi (1996), who stated that midwives as practitioners have little approval in community health services; low appreciation of their jobs, low evaluation of their skills and techniques, and an ambiguity in priority for employment as professional midwives. This situation needs to be discussed more openly.

Table 1 shows that $53.1 \%$ of $\mathrm{M}$-communities considered further employment of midwives compared with $22.0 \%$ or less of other communities. This difference was statistically significant, and may suggest that $\mathrm{M}$-communities better understand the need for more midwives as staff. This was the conclusion already reached by Omine et al. (2004).

Table 3 shows that $\mathrm{M}$-communities have a higher demand for midwives in all $\mathrm{MCH}$ services except four as described in the results above.

Despite the fact that among the 285 communities, $42.5 \%$ were $\mathrm{PM}$-communities employing a total of 416 PHNs or 3.4 average staff per community (Table 1 ), it could still be difficult for the midwife professional to fully excel as there was no significant difference in the rate of fulfillment of $\mathrm{MCH}$ services between $\mathrm{PM}^{-}$and $\mathrm{P}$-communities, as seen in Table 4.

Table 4 shows that the fulfillment rates in 7 health services were higher in $\mathrm{M}$-communities than in the other communities. These results indicate that more midwives should be employed as full-time workers in the other two communities, since there was no statistically significant difference in the services they provide (Table 1).

Only $11.2 \%$ of the communities employed midwives as full-time workers. They were engaged in professional work to meet a variety of needs in health services and practices. Midwives were producing more effective results in seven MCH services, even though they were fewer in number compared with PHNs.

As an indication of the evaluation of $\mathrm{MCH}$ services, about half of $\mathrm{M}$-communities declared they needed midwives, indicating that they approved the role of midwives and their necessity. On the other hand, $75.2 \%$ of $\mathrm{PM}$-communities raised reasons not to need them, indicating the midwife license was not so highly evaluated, even if their PHNs had the license.

Seiichi Oda, the former section chief of the Maternal and Child Health Division of the Children and Family Bureau, Ministry of Health, Labor and Welfare, intended to recommend midwives as fulltime staff members. Oda and his colleagues (Oda et al., 1998) stated that "so far, PHNs have been employed as the main $\mathrm{MCH}$ manpower in the communities. Generally speaking, in order to operate $\mathrm{MCH}$ services more professionally and effectively, midwives should be more involved. Historically, midwives were not employed in administrative posts ; instead PHNs were involved in this area as well. However, in the area of public health services in the communities, midwives should be employed in equal proportion to PHNs as a manpower resource." This favorable statement from the Ministry should have given midwives a greater 
chance to be employed as full-time workers in the communities.

At the present time, health care workers are confronted with a variety of problems each day, such as abuse, adolescent problems and domestic violence, to name a few. It is therefore necessary for the health leaders in the communities to emphasize further the importance of infant and child rearing and the related problems of mother-child health. Midwives could play a more important role in this, since they could directly engage in these maternal affairs in a continuous transition from pregnancy to child care.

Kondo (1999) stated that it is important for midwives to broaden their background to enable them to distinguish a wider range of health problems, and confidently work with their own professional skills in regional services such as home visits. In this sense, it is preferable to have midwives as full-time workers and utilize their maximum abilities to the fullest for the health benefit of the community. If this enhanced midwife participation could be achieved, it would provide maximum support for the regional $\mathrm{MCH}$ services.

In the US, UK and New Zealand, midwives are not only socially admitted in the medical system and $\mathrm{MCH}$ services, they can also operate independently. Midwives are also dominant in other regional community activities in such communities (Green et al., 2000 ; Kato, 2003).

In our country, the health services are perceived in a different perspective. Each administrative community has different health care needs, and it is difficult to compare them with each other. However, in the US midwives are admitted as nurse-midwives; as specialists they engage not only in a variety of women health problems such as pregnancy, birth, child care, etc., but also cover areas from puberty to senescence and domestic violence. They also engage in perinatal care through instruc- tion and class activities in the support of infant rearing programs, and perform in the relevant facilities such as the community health centers (Kawagoe et al., 2000 ; Osborne et al., 2005).

As for the competency of community midwives, the following criteria are required of them (Osborne et al., 2005 ; Stuart and Oshio, 2002) : 1) By improving their techniques and knowledge, midwives should be capable of discriminating general community health problems as well as those particular to the needs of women or families. 2) Midwives should be capable of preparing a caring birth environment that guarantees the safety of delivery. 3) Midwives should be capable of mutual respect for doctors, nurses, other midwives, health care workers and staff, and able to build relationships enabling open exchange of opinions with each other. In this way, mistakes and accidents can be avoided, and a better system created and maintained.

In conclusion, our local communities, prefectural and national government agencies should seriously consider improving the status of midwives through better education and better job opportunities. Our study showed that midwives are indeed needed as full-time workers in the community, for they can offer the most comprehensive health services. Moreover, health care professionals and community leaders connected with $\mathrm{MCH}$ services should actively discuss the issue of full-time midwife employment in Japan. Our results showed that $\mathrm{MCH}$ services were lower and the absence of midwives felt less in $\mathrm{PM}$-communities, and perhaps related to this, even those PHNs holding midwife licenses, were not so highly evaluated.

On the contrary, $\mathrm{MCH}$ services and the awareness of the need for midwives were more developed in $\mathrm{M}-$ communities. This would suggest that midwives working full-time were manifesting their fully motivated professionalism. This points 
to the necessity of training midwives with the highly professional skills truly relevant to the midwife license. Local communities and prefectural governments should consider increasing the employment of regular midwives to provide optimal MCH services. Furthermore, for these purposes it is necessary to reform current midwife training into an education system providing genuine midwives with practical power.

The timing for midwives to get involved and to achieve full-time employment, is most appropriate now, since local $\mathrm{MCH}$ services have adopted the slogan "Healthy parents and children 21 " to help promote better health care in the community in the 21 st century.

\section{Acknowledgement}

This study was possible with the cooperation and encouragement of the Japanese Society of Midwifery Education 2002. We express our thanks to all the 285 participant communities who graciously answered the questionnaire in this survey. We would like to express our deepest gratitude to our senior colleague, Liu Asato, for his invaluable contribution to making this paper possible.

\section{References}

Green JM, Renfrew MJ and Curtis PA (2000) : Continuity of carer ; What matters to women? A review of the evidence, Midwifery, 16, 186-196

Japan Nursing Society (2002) : Data and statistics in nursing, Compiled by the research group for the troubles in nursing, 6-7, Japanese Nursing Association (Tokyo)

Kano N and Komatsu M (2001) : Study on the midwifery activities and training midwives in the facilities for the maternal and child health-Based on the second survey in Ibaraki prefecture-, Medical Jour- nal of Ibaraki Prefectural Hospital, 19, 11-17.

Kato N (2000) : Study on effective progress in maternal and child health activities, in the report of home research for children, supported by the science research expenses of the Ministry of Health Welfare and Labour, 227-271, Japanese Midwives Association (Tokyo)

Kato N (2001) : Report for the study on effective midwifery activities supporting child rearing in the communities, supported by the Fund for Social Welfare and Medical Enterprise to support infant-rearing in 2000, 221-222, Japanese Midwives' Association (Tokyo)

Kato N (2003) : Different cultures and midwifery activities, Japanese Midwifery Journal, 17, 54-59

Kawagoe A, Kato N, Imazaki S et al. (2000) : Report from the survey on the need and supply of midwives, supported by the foundations for a countermeasure to ensure training co-medical staffs, 1999, (Improvement project for midwifery services), Japanese Midwifery Journal, 17, 54-59

Kondo J (1999) : Perspective of the education for midwives, Japanese Journal of Midwives, 53, 42-45

Noguchi M (1996) : Relationship between the approval of midwives in their jobs and the degree of their satisfaction in it, J Jpn Acad Nurs Sci, 16, 48-57

Oda S, Takahara R and Matsutani Y (1998) : Expectation of the practices in health services in the communities as autonomies, Monthly Health Center of Federation of Health Centers in all Nations, vol. 1, 1218, Japan Federation of Municipal Health Centers (Tokyo)

Omine F, Tamashiro Y, Shimajiri S et al. (2004) : Study on the number of midwives needed in an area to engage in maternal and child health programs, Japanese Journal of Maternal Health, 45, 41-49

Osborn K, Stone S, Eunice K et al. (2005) : The development of the community-based nurse-midwifery education program; an innovation in distance learning, Journal of Midwifery \& Women's Health, 50, 138-145

Stuart D and Oshio S (2002) : Primary care in nurse ${ }^{-}$ midwifery practice-A national survey-, Journal of Midwifery \& Women's Health, 47, 104-109

(Received 4.27.2007 ; Accepted 6.19.2008) 